\title{
Formation of $\delta$-Aminovaleric Acid from Proline, Ornithine and Arginine by Rumen Ciliate Protozoa
}

\author{
Ryoji ONODERA, Wakao TSUTSUMI and Makoto Kandatsu* \\ Department of Agricultural Chemistry, Miyazaki University, Miyazaki, Japan \\ *Azabu Veterinary College, Fuchinobe, Sagamihara-shi, Japan \\ Received May 13, 1977
}

\begin{abstract}
Abilities of washed suspension of rumen ciliate protozoa to form $\delta$-aminovaleric acid (DAV) and some precursors of DAV were chromatographically and autoradiographically examined. DAV was accumulated linearly in the medium during incubation of the ciliates. When proline or ornithine was added to the medium, the amount of DAV was increased to the level over the control value. The amount of proline in the medium after incubation was increased by addition of ornithine, while the amount of ornithine was increased by addition of arginine. L-Proline-U. ${ }^{14} \mathrm{C}$ was converted to radioactive DAV by the ciliates. But the radioactive DAV was not converted further by them, so it seemed to be the end product in proline metabolism of rumen ciliates. L-Ornithine-U- ${ }^{14} \mathrm{C}$ was converted to proline and DAV, and L-arginine- $\mathrm{U}-{ }^{14} \mathrm{C}$ was converted to ornithine, proline, DAV and four other unidentified compounds by the ciliates. All these results led us to presume that the serial pathway such as from arginine to ornithine, from ornithine to proline and from proline to DAV would exist in biochemical systems of rumen ciliate protozoa.
\end{abstract}

There have been some reports about the formation of $\delta$-aminovaleric acid (DAV) by some kinds of bacteria. Stickland has shown that washed suspensions of Clostridium sporogenes activated alanine, valine and leucine as $\mathrm{H}$ donators, and glycine, proline and hydroxyproline as $\mathrm{H}$ acceptors, ${ }^{11}$ and reduced $l$-proline by oxidation of alanine, to DAV. ${ }^{2}$ Woods ${ }^{3}$ has continued the work of Stickland on coupled reactions and reported that $d$ arginine and $d$-ornithine are both activated as $\mathrm{H}$ acceptors and partly deaminated in the absence of $\mathbf{H}$ donators, and that ornithine coupled with alanine is deaminated to DAV. Later on, El-Shazly ${ }^{4}$ has also revealed that L-proline in the presence of other amino acids was reduced to DAV by rumen microorganisms. Another evidence has been presented by Dehority et al. ${ }^{5)}$ that L-proline- ${ }^{14} \mathrm{C}$ underwent reductive ring cleavage to give $\mathrm{DAV}$ which was further deaminated at $\delta$-position to form valeric acid by rumen microorganisms in vitro. Thereafter, Lewis and Emery ${ }^{6)}$ have shown the formation of ornithine, DAV and putrescine from L-arginine and of DAV and putrescine from ornithine by rumen microorganisms. Stadtman ${ }^{7}$ has partially purified the proline reductase from a clostridium which catalyzes a quantitative reduction of DL-proline to DAV and requires NAD, $\mathrm{Mg}^{2+}$ and pyridoxal phosphate as the cofactors. Costilow and Laycock ${ }^{81}$ have found proline as an intermediate in the reductive deamination of ornithine to DAV by fresh extracts of cells of Clostridium botulinum.

On the other hand, DAV has also been identified as a reaction product of deamination of L-lysine by an enzyme from a strain of Streptomyces ${ }^{9}$ and from Pseudomonas. ${ }^{10)}$ Lewis and Emery ${ }^{6}$ ) have shown the production of DAV and cadaverine from L-lysine by rumen microorganisms, but Onodera and Kandatsu ${ }^{11}$ have denied their results by showing that not DAV and cadaverine but butyric and acetic acids were produced as metabolites of lysine by rumen microorganisms by using radioactive lysine.

As far as we know, there have been no report on the metabolism of DAV by protozoa. In connection with our detection of DAV 
in the culture medium of rumen ciliate protozoa, ${ }^{12)}$ present paper describes about the metabolic, pathway for the formation of DAV by rumen ciliate protozoa.

\section{MATERIALS AND METHODS}

1. Isolation of rumen ciliate protozoa. Rumen ciliates were obtained by the method based on those described in previous paper ${ }^{12)}$ from a fistulated goat (female, body wt.: $45 \mathrm{~kg}$ ) maintained on daily rations consisting of $3 \sim 5 \mathrm{~kg}$ of fresh grass; $300 \mathrm{~g}$ of starch pulp and $200 \mathrm{~g}$ of mixed concentrates.

\section{Cultural methods and treatment of samples}

a) Experiment to know the accumulation of DAV in the medium without substrates. Twenty five $\mathrm{ml}$ of rumen ciliate protozoan suspension (protozoan concentration: $4 \%(v / v)$ in $\mathrm{B}-9$ buffer solution $\left.{ }^{13)}\right)$ were incubated at $39^{\circ} \mathrm{C}$ in $30 \mathrm{ml}$ of conical flask containing $1.25 \mathrm{mg}$ of dihydrostreptomycin sulfate to inhibit the action of contaminating bacteria. ${ }^{14)}$ After incubation, $5 \mathrm{ml}$ of the suspension were withdrawn with stirring at $0,4,8$ and $12 \mathrm{hr}$, respectively, mixed with one $\mathrm{ml}$ of $60 \%$ trichloroacetic acid (TCA), left over night in a cold room and filtered through Toyo Filter Paper No. 5C. Sediments remained on the filter paper were washed three times with $5 \mathrm{ml}$ of $10 \%$ TCA and the filtrate was washed three times with almost equal volume of ethyl ether to remove TCA, concentrated to dryness in vacuo and submitted to the determination of DAV by an amino acid autoanalyzer.

b) Experiment with non-labeled amino acids added to the medium. Each $5 \mathrm{ml}$ of rumen ciliate protozoan suspension prepared in the same manner as that mentioned above was incubated with $250 \mu \mathrm{g}$ of dihydrostreptomycin sulfate at $39^{\circ} \mathrm{C}$ for $12 \mathrm{hr}$ in $10 \mathrm{ml}$ of conical flask to which $5 \mu$ mole of each amino acid shown in Table I was added separately or together previously. In these experiments, incubation of the ciliate suspension without amino acid was paralleled as a control. After incubation, each sample was treated in the same manner as those described in $a$ ).

c) Experiment with radioactive amino acids added to the medium. Eight $\mathrm{ml}$ of the rumen ciliate suspension mentioned above were transferred to a conical flask $(30 \mathrm{ml})$, to which $8 \mu$ mole of L-proline and $10 \mu \mathrm{Ci}$ of L-proline- $\mathrm{U}-{ }^{14} \mathrm{C}, 8 \mu$ mole of L-ornithine and $10 \mu \mathrm{Ci}$ of L-ornithine- $\mathrm{U}^{11} \mathrm{C}$ or $8 \mu$ mole of $\mathrm{L}$-arginine and $10 \mu \mathrm{Ci}$ of L-arginine- $\mathrm{U}-{ }^{14} \mathrm{C}$ and $800 \mu \mathrm{g}$ of dihydrostreptomycin sulfate were added previously, and stirred. Four $\mathrm{ml}$ of the suspension containing each amino acid were transferred again into a Warburg flask having a center well, to which about $0.7 \mathrm{ml}$ of
$20 \% \mathrm{KOH}$ was added previously to trap $\mathrm{CO}_{2}$, and incubated at $39^{\circ} \mathrm{C}$ for $12 \mathrm{hr}$ after the air phase of the flask was replaced with $\mathrm{N}_{2}$ gas; whereas $5 \mu \mathrm{l}$ of the remaining suspension was used for the determination of total radioactivity, and to the rest of the suspension was added one $\mathrm{ml}$ of $50 \% \mathrm{TCA}$ as a sample before incubation.

In the case of the incubation with radioactive DAV, $4 \mathrm{ml}$ of the ciliate suspension were directly transferred to the Warburg flask to which $8 \mu$ mole of DAV, $31,200 \mathrm{cpm}$ (determined by GM counter) of radioactive DAV and $400 \mu \mathrm{g}$ of dihydrostreptomycin sulfate were added previously, and incubated similarly after subjecting $5 \mu \mathrm{l}$ to the determination of total radioactivity.

After incubation in both cases, one $\mathrm{ml}$ of $50 \% \mathrm{TCA}$ was added to the side chamber of the flask and poured into the main chamber and the flask was left over night in a cold room. Then, $\mathrm{KOH}$ solution in the center well was filled up to $10 \mathrm{ml}$ with water and an amount of $0.5 \mathrm{ml}$ of the solution was withdrawn into a stainless disc or a vial to measure radioactivity in trapped $\mathrm{CO}_{2}$. Culture medium was divided into two parts, supernatant fluid and precipitates (ciliates), by centrifugation at $120 \times g$ for $30 \mathrm{sec}$. The precipitates was washed five times with $10 \%$ TCA and once with water. The precipitates obtained was hydrolysed with $6 \mathrm{~N} \mathrm{HCl}$ at $110^{\circ} \mathrm{C}$ for $20 \mathrm{hr}$ in a sealed tube and filtered through glass filter (3G4) to remove humin. The filtrate was evaporated to dryness in vacuo and submitted to the determination of radioactivity and to paper chromatography. The supernatant fluid containing the washings of the precipitates was washed three times with ether to remove TCA and other ethersoluble substances. After about $50 \mathrm{ml}$ of water was added to the ether fraction, the solution was neutralized with $40 \% \mathrm{NaOH}$, using phenolphthalein as an indicator, and was evaporated and submitted to the determination of radioactivity. The water-soluble fraction was concentrated to $10 \mathrm{ml}$ and $5 \mu 1$ was withdrawn and submitted to the determination of radioactivity. Remaining solution was desalted by percolation through a bed $(1 \mathrm{~cm} \times 5 \mathrm{~cm})$ of 'Amberlite' CG-120 (H form) resin. After washing the bed with $150 \mathrm{ml}$ of water, the effluent was neutralized, concentrated to $10 \mathrm{ml}$ and $0.5 \mathrm{ml}$ was submitted to the determination of radioactivity. The fraction containing amino acids adsorbed in the bed was eluted with $200 \mathrm{ml}$ of $2 \mathrm{~N} \mathrm{NH}_{4} \mathrm{OH}$. The eluate was taken to dryness and submitted to paper chromatography.

\section{Analytical method}

Non-radioactive amino acids were determined by an Amino Acid Autoanalyzer (Model: AA-100, Sibata Chemical APP. MFG. Co., Ltd.).

Paper chromatography was carried out by using (1) n-BuOH: AcOH: $\mathrm{H}_{2} \mathrm{O}(4: 1: 2)$ and (2) Phenol: $\mathrm{H}_{2} \mathrm{O}$ 
(4:1) as solvents for two dimensional developments. But in the case of the experiment with $\mathrm{L}$-arginine- $\mathrm{U}$ ${ }^{14} \mathrm{C}$, the solvent consisting of $\mathrm{EtOH}, \mathrm{H}_{2} \mathrm{O}$ and $\mathrm{NH}_{4} \mathrm{OH}$ (18: 1:1) was used instead of the solvent (2).

Autoradiogram was made by exposing X-ray film $(25.4 \mathrm{~cm} \times 30.5 \mathrm{~cm}$, Fuji Photo Film Co., Ltd.) to the paper chromatogram for 10 days in case of the experiment using radioactive DAV and for 6 days in case of the experiment using other ${ }^{14} \mathrm{C}$ labeled amino acids.

Radioactivities of amino acids were determined after cutting off the spots of radioactive amino acids on the paper chromatograms (detected through their autoradiograms) and extracting them with water.

Radioactivity was measured by a GM counter (Aloka Handy Scaler, Model: TDC-101, Japan Radiation \& Medical Electronics, Inc.) in the experiments with radioactive proline and DAV, and by a Liquid Scintillation. Spectrometer (Model: 3320, Packard) using 2,5-diphenyloxazole (PPO) (4 g/liter) and 1, 4bis-2-(5-phenyloxazoyl)-benzene (POPOP) $(0.1 \mathrm{~g} /$ liter) as fluorescent substances dissolved in mixed solvents consisting of toluene, ethyl cellosolve and dioxane $(1: 1: 1)$ and containing naphthalene $(100 \mathrm{~g} /$ liter $)$ in the experiments with radioactive ornithine and arginine.

\section{Chemicals}

L-Ornithine and other amino acids were supplied by Nakarai Chemicals, Ltd. and Ajinomoto Co., Inc., respectively.

L-Proline-U- ${ }^{14} \mathrm{C}$ (Sp. Act.: $216 \mathrm{mCi} / \mathrm{mm}$ ) and Larginine-U- ${ }^{14} \mathrm{C}$ (Sp. Act.: $175 \mathrm{mCi} / \mathrm{mm}$ ) were supplied by Daiichi Pure Chemicals Co., Ltd. L-Ornithine-U- ${ }^{14} \mathrm{C}$ was supplied by New England Nuclear.

Radioactive DAV was obtained by extracting the spot of DAV (detected through autoradiogram) in the paper chromatogram of the supernatant fluid of the medium in which rumen ciliates had been incubated with I-proline-U- ${ }^{14} \mathrm{C}$ alone at $39^{\circ} \mathrm{C}$ for $12 \mathrm{hr}$ in the same manner as mentioned in $2 . c$ ).

\section{RESULTS AND DISCUSSION}

In the preliminary examination, the amount of DAV accumulated in the course of incubation time in the medium by rumen ciliate protozoa was determined and almost linear increase of DAV ranging from $39(0 \mathrm{hr})$ to $186 \mathrm{nmole} / \mathrm{ml}(12 \mathrm{hr})$ was observed during incubation. Then, in order to investigate the precursors for the formation of DAV by rumen ciliates, amino acids, regarded as the constituents of the rumen ciliate protein, and ornithine were separately added to the medium and incubated with rumen ciliates for $12 \mathrm{hr}$. As a result, proline and ornithine specifically increased the amount of DAV beyond the level of the control; the medium of the control contained no substrate; while other amino acids did not increase the amount of DAV (Table I). As shown in Table II, when amino acid mixture shown in Table $I$ other than proline and ornithine was added to the medium, the amount of DAV $(142 \mathrm{nmole} / \mathrm{ml})$ produced by rumen ciliates decreased during $12 \mathrm{hr}$ incubation to the level less than that without substrate $(186 \mathrm{nmole} / \mathrm{ml})$, whereas addition of proline together with the amino acid mixture mentioned above to the medium distinctly increased the amount of DAV $(233 \mathrm{nmole} / \mathrm{ml})$ over the level produced by addition of the amino acid mixture other than proline and ornithine (142 nmole/ml). But this level (233 $\mathrm{nmole} / \mathrm{ml}$ ) was much lower than that yielded by addition of proline alone to the medium $(401 \mathrm{nmole} / \mathrm{ml})$. From these results, DAV seemed to be derived from proline and ornithine, and starved protozoa seemed to stimulate the formation of DAV from proline.

Next, the positive effect of addition of individual amino acids shown in Table $I$ into the medium upon the production of proline or ornithine by rumen ciliates was examined. As shown in Table I, addition of ornithine distinctly increased the amount of proline to the level over the control, while addition of other amino acids except for arginine (in the experiment with arginine, we failed to determine the amount of proline) did not have such effect. On the other hand, the amount of ornithine, which was rather low among endogenous amino acids of the ciliates, was increased markedly by the addition of arginine alone during incubation. These results led us to presume that the successive pathway such as from arginine to ornithine, from ornithine to proline and from proline to DAV would exist in biochemical systems of rumen ciliates. To confirm these presumption, the corresponding radioactive amino acids were used in the following experiments. 
Table I. Effect of Addition of Each Amino Acid to the Medium upon the Production of DAV, ${ }^{a)}$ Proline and Ornithine by Mixed Rumen Ciliates

Incubation time: $12 \mathrm{hr}$, Unit: nmole/ml.

\begin{tabular}{|c|c|c|c|c|c|c|}
\hline \multirow{2}{*}{ Amino acid added } & \multicolumn{2}{|c|}{$\mathrm{DAV}^{a)}$} & \multicolumn{2}{|c|}{ Proline } & \multicolumn{2}{|c|}{ Ornithine } \\
\hline & Amt. & Ratio & Amt. & Ratio & Amt. & Ratio \\
\hline Non & 216 & 1.00 & 91 & 1.00 & 11 & 1.00 \\
\hline Asp & 214 & 0.99 & 66 & 0.73 & 12 & 1.09 \\
\hline Thr & 227 & 1.05 & 73 & 0.80 & 12 & 1.09 \\
\hline Ser & 207 & 0.96 & 89 & 0.99 & 13 & 1.18 \\
\hline Glu & 251 & 1.16 & 73 & 0.80 & 17 & 1.55 \\
\hline Pro & 352 & 1.63 & - & - & 12 & 1.09 \\
\hline Gly & 265 & 1.22 & 73 & 0.80 & 15 & 1.36 \\
\hline Ala & 239 & 1.11 & 86 & 0.95 & 17 & 1.55 \\
\hline Cys & 160 & 0.74 & 115 & 1.26 & 12 & 1.09 \\
\hline Val & 225 & 1.04 & 62 & 0.68 & 12 & 1.09 \\
\hline Met & 218 & 1.01 & 104 & 1.14 & 13 & 1.18 \\
\hline Leu & 260 & 1.20 & 93 & 1.02 & 15 & 1.36 \\
\hline Ileu & 231 & 1.07 & 64 & 0.70 & 14 & 1.27 \\
\hline Tyr & 219 & 1.01 & 86 & 0.95 & 12 & 1.09 \\
\hline Phe & 187 & 0.87 & 93 & 1.02 & 14 & 1.27 \\
\hline His & 253 & 1.17 & 86 & 0.95 & 15 & 1.36 \\
\hline Orn $^{b)}$ & 307 & 1.42 & 204 & 2.24 & - & - \\
\hline Lys & 235 & 1.09 & 86 & 0.95 & 12 & 1.09 \\
\hline Arg & 222 & 1.03 & - & - & 62 & 5.64 \\
\hline
\end{tabular}

a) DAV: $\delta$-Aminovaleric acid. b) Orn: Ornithine

One $\mu \mathrm{mole} / \mathrm{ml}$ of each amino acid was added into the medium.

Composition of ciliates in this expt.

Entodiniinae, Diplodiniinae, 4,656

56

Dasytricha

$26 \times 10^{2} / \mathrm{ml}$

Table II. Effect of Addition of Amino Acids Mixture to the Medium Upon the ProducTION OF $\mathrm{DAV}^{a}{ }^{\text {) }}$ BY MIXED RUMEN

$$
\text { Ciliates }
$$

Incubation time: $12 \mathrm{hr}$, Unit: nmole/ml.

\begin{tabular}{ccccc}
$\begin{array}{c}\text { Substrates } \\
\text { added }\end{array}$ & Non & Pro & $\begin{array}{c}\text { Amino } \\
\text { acid mixt. }\end{array}$ & $\begin{array}{c}\text { Amino } \\
\text { acid mixt. } \\
+ \text { Pro }\end{array}$ \\
$\begin{array}{c}\text { DAV } \\
\text { yielded }\end{array}$ & 186 & 401 & 142 & 233 \\
\hline
\end{tabular}

a) DAV: $\delta$-Aminovaleric acid.

Amino acid mixt.: The mixture of each amino acid shown in Table II. Other than proline and ornithine.

One $\mu \mathrm{mole} / \mathrm{ml}$ of each amino acid was added into the medium.

Composition of ciliates in this expt.

Entodiniinae, Diplodiniinae, Dasytricha $1060 \quad 242 \quad 6 \quad \times 10^{2} / \mathrm{ml}$

Firstyl, L-proline-U- ${ }^{14} \mathrm{C}$ was incubated for $12 \mathrm{hr}$ with rumen ciliates and the results were shown in Table III. Since the radioactivities

found in $\mathrm{CO}_{2}$ and ether-soluble fraction of the medium with ciliates after incubation were almost equal, to those without the ciliates, rumen ciliates did not seem to produce not only $\mathrm{CO}_{2}$ but also ether-soluble substances such as volatile fatty acids from L-proline. Most of the radioactivity was found in watersoluble fraction even after incubation with the ciliates. Autoradiogram of the paper chromatogram of the supernatant fluid of the medium after $12 \mathrm{hr}$ incubation with ciliates clearly revealed the formation of DAV from proline (Fig. 1a). DAV formed was accounted for $0.146 \mu \mathrm{mole} / \mathrm{ml}$ which was equivalent to $14.6 \%$ of proline added. Since the radioactive spot on the paper chromatogram of the hydrolysate of rumen ciliates after $12 \mathrm{hr}$ incubation was autoradiographically revealed to be only proline, proline seemed to be incorporated unchanged into the ciliate protein. 
TABle III. Conversion of L-Proline-U- ${ }^{14} \mathrm{C}$ to Radioactive DAV ${ }^{a}$ ) BY MiXed Rumen CILIATES

\begin{tabular}{|c|c|c|c|c|}
\hline \multirow{2}{*}{$\begin{array}{l}\text { Incubation time, hr } \\
\text { Fractions }\end{array}$} & \multicolumn{2}{|c|}{0} & \multicolumn{2}{|c|}{12} \\
\hline & $\begin{array}{l}\text { Radioactivity } \\
(\mathrm{cpm} / \mathrm{ml})\end{array}$ & $\begin{array}{l}\text { Percentage } \\
(\%)\end{array}$ & $\begin{array}{l}\text { Radioactivity } \\
(\mathrm{cpm} / \mathrm{ml})\end{array}$ & $\begin{array}{c}\text { Percentage } \\
(\%)\end{array}$ \\
\hline Total & 86,500 & 100 & 86,500 & 100 \\
\hline Proline in supernate ${ }^{b}$ ) & 85,948 & 99.4 & 71,675 & 82.9 \\
\hline $\mathrm{DAV}^{(a)}$ in supernate $\left.{ }^{b}\right)$ & 0 & 0 & 12,600 & 14.6 \\
\hline Ciliates & 35 & 0.04 & 1,698 & 2.0 \\
\hline Others & 375 & 0.50 & 411 & 0.43 \\
\hline
\end{tabular}

a) DAV: $\delta$-Aminovaleric acid. b) Supernate: Supernatant fluid.

$$
\begin{array}{cccc}
\multicolumn{4}{c}{\text { Composition of ciliates in this expt. }} \\
\text { Entodiniinae, } & \text { Diplodiniinae, } & \text { Dasytricha } & \\
1228 & 176 & 6 & \times 10^{2} / \mathrm{ml}
\end{array}
$$
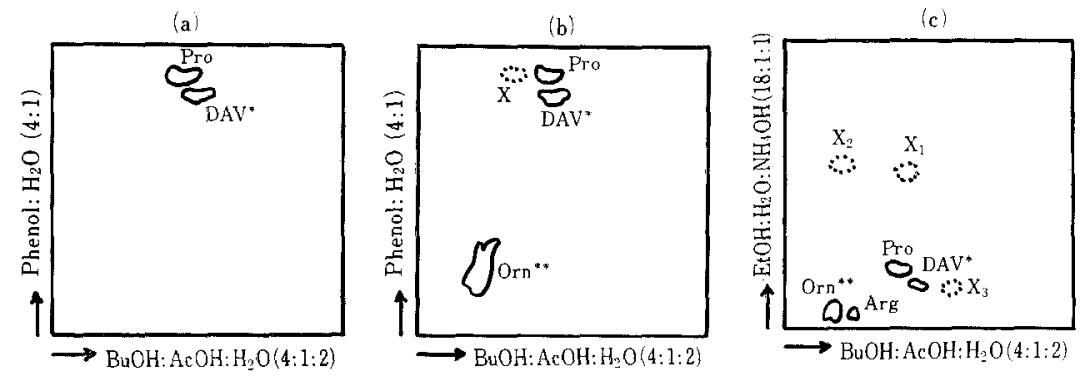

$\mathrm{DAV}^{*}: \delta$-aminovaleric acid, Orn**: ornithine

FIG. 1. Autoradiogram of Amino Acids Found in the Supernatant Fluid of the Culture Medium of Rumen Ciliates after $12 \mathrm{hr}$ Incubation with L-Proline-U- ${ }^{14} \mathrm{C}(\mathrm{a})$, L-Ornithine-U. ${ }^{14} \mathrm{C}(\mathrm{b})$ and L-ArginineU-19 C (c).

In the case of the medium without ciliates, radioactive proline remained unchanged in the medium even after incubation at $39^{\circ} \mathrm{C}$ for $12 \mathrm{hr}$.

Then, radioactive DAV was added to the medium and incubated with rumen ciliates similarly at $39^{\circ} \mathrm{C}$ for $12 \mathrm{hr}$ to know the fate of DAV. But DAV remained unchanged in the medium even after incubation, so it seemed to be the end product in proline metabolism of rumen ciliates (Table IV).

In the next experiment, metabolism of Lornithine by rumen ciliates was examined by using radioactive one. As shown in Table V, radioactivities could scarecely be detected in carbon dioxide and ether-soluble fractions even after incubation with ciliates like the result in the case of radioactive proline. Most of the radioactivity was found in the watersoluble fraction in which $76.3 \%$ of added
TABle IV. Stability of Radioactive DAVa) Added in the Culture Medium of Mixed Rumen Ciliates

Incubation time: $12 \mathrm{hr}$.

\begin{tabular}{lc}
\hline \multicolumn{1}{c}{ Fractions } & $\begin{array}{c}\text { Radioactivity } \\
\text { (cpm/ml) }\end{array}$ \\
\hline Total (Before incubation) & 7800 \\
DAV $^{()}$in supernatant fluid & 7200 \\
Ciliates & 45 \\
Others & 225 \\
\hline
\end{tabular}

DAV: ${ }^{a} \delta$-Aminovaleric acid.

Composition of ciliates in this expt.

Entodinitinae, Diplodinitnae, Dasytricha $1862 \quad 358 \quad 10 \times 10^{2} / \mathrm{ml}$

ornithine remained unchanged, and 0.179 and $0.020 \mu \mathrm{mole} / \mathrm{ml}$ of proline and $\mathrm{DAV}$, respectively, and an unidentified spot were autoradiographically detected after $12 \mathrm{hr}$ incubation with the ciliates (Fig. 1b). Since the unidentified radioactive compound was simi- 
Table V. Conversion of L-Ornithine-U-U ${ }^{14} \mathrm{C}$ to Radioactive Proline AND DAV ${ }^{a)}$ BY Mixed RUMEN CiLIATES

\begin{tabular}{|c|c|c|c|c|c|c|}
\hline \multirow[t]{2}{*}{ Incubation time, hr } & \multicolumn{3}{|c|}{0} & \multicolumn{3}{|c|}{12} \\
\hline & $\begin{array}{c}\text { Radio- } \\
\text { activity } \\
\text { (cpm/ml) }\end{array}$ & $\begin{array}{c}\text { Molar } \\
\text { amt. }{ }^{b)} \\
(\mu \mathrm{mole} / \mathrm{ml})\end{array}$ & $\begin{array}{c}\text { Percentage } \\
(\%)\end{array}$ & $\begin{array}{l}\text { Radio- } \\
\text { activity } \\
\text { (cpm/ml) }\end{array}$ & $\begin{array}{c}\text { Molar } \\
\text { amt. }{ }^{b)} \\
(\mu \mathrm{mole} / \mathrm{ml})\end{array}$ & $\begin{array}{c}\text { Percentage } \\
(\%)\end{array}$ \\
\hline Without ciliates & & & & & & \\
\hline Total & $2,287,625$ & 1.005 & 100 & $2,287,625$ & 1.005 & 100 \\
\hline Ornithine in supernate ${ }^{c}$ & $2,253,852$ & 0.990 & 98.5 & $2,191,750$ & 0.964 & 95.9 \\
\hline Unidentified compd. in & & & & & & \\
\hline supernate $^{o>}$ & 0 & - & - & 59,970 & - & - \\
\hline $\begin{array}{l}\text { Others } \\
\text { With ciliates }\end{array}$ & 29,855 & - & - & 29,281 & - & - \\
\hline Total & $2,268,560$ & 1.005 & 100 & $2,268,560$ & 1.005 & 100 \\
\hline Ornithine in supernate ${ }^{c)}$ & $2,238,760$ & 0.992 & 98.7 & $1,730,520$ & 0.767 & 76.3 \\
\hline Proline in supernate ${ }^{c)}$ & 0 & 0 & 0 & 404,010 & 0.179 & 17.8 \\
\hline $\left.\mathrm{DAV}^{a}\right\rangle$ in supernate ${ }^{c)}$ & 0 & 0 & 0 & 44,890 & 0.020 & 2.0 \\
\hline $\begin{array}{l}\text { Unidentified compd. in } \\
\text { supernate }^{(>)}\end{array}$ & 0 & - & - & 60,750 & - & - \\
\hline Ciliates & 0 & - & - & 5,000 & - & - \\
\hline Others & 27,550 & - & - & 26,598 & - & - \\
\hline
\end{tabular}

DAVa) $\delta$-Aminovaleric acid. b) Molar amt. was calculated from the Sp. Act. ${ }^{c}$ Supernate: Supernatant fluid.

\begin{tabular}{cccc}
\multicolumn{5}{c}{ Composition of ciliates in this expt. } \\
Entodiniinae, & Diplodiniznae, & Dasytricha & \\
2228 & 138 & 16 & $\times 10^{2} / \mathrm{ml}$
\end{tabular}

TABle VI. CONVERSion OF L-ARginine-U-14C to Radioactive Ornithine, Proline and DAV $\left.{ }^{a}\right)$ by Mixed Rumen Cillates

\begin{tabular}{|c|c|c|c|c|c|c|}
\hline \multirow{2}{*}{$\begin{array}{l}\text { Incubation time, hr } \\
\text { Fractions }\end{array}$} & \multicolumn{3}{|c|}{0} & \multicolumn{3}{|c|}{12} \\
\hline & $\begin{array}{c}\text { Radio- } \\
\text { activity } \\
\text { (cpm/ml) }\end{array}$ & $\begin{array}{c}\text { Molar } \\
\left.\text { amt. } .^{b}\right) \\
(a \text { mole } / \mathrm{ml})\end{array}$ & $\begin{array}{c}\text { Percentage } \\
(\%)\end{array}$ & $\begin{array}{l}\text { Radio- } \\
\text { activity } \\
\text { (cpm/mi) }\end{array}$ & $\begin{array}{c}\text { Molar } \\
\text { amt. } .^{b} \\
(\mu \mathrm{mole} / \mathrm{ml})\end{array}$ & $\begin{array}{c}\text { Percentage } \\
(\%)\end{array}$ \\
\hline Total & $2,480,900$ & 1.007 & 100 & $2,480,900$ & 1.007 & 100 \\
\hline Carbon dioxide & - & - & - & 216,390 & 0.527 & 52.3 \\
\hline \multicolumn{7}{|l|}{$\begin{array}{l}\text { Amino compd. in } \\
\text { supernate }^{a)}\end{array}$} \\
\hline Arginine & $2,441,850$ & 0.991 & 98.4 & 475,880 & 0.193 & 19.2 \\
\hline Ornithine & 0 & 0 & 0 & $1,144,915$ & 0.558 & 55.4 \\
\hline Proline & 0 & 0 & 0 & 371,476 & 0.181 & 18.0 \\
\hline $\left.\mathrm{DAV}^{a}\right)$ & 0 & 0 & 0 & 17,540 & 0.008 & 0.8 \\
\hline$X_{1}^{d)}$ & 0 & - & - & 47,609 & - & - \\
\hline $\mathrm{X}_{2}{ }^{d)}$ & 0 & - & - & 22,134 & - & - \\
\hline $\mathrm{X}_{3}{ }^{d\rangle}$ & 0 & - & - & 7,726 & - & - \\
\hline Ciliates & 830 & - & - & 55,980 & - & - \\
\hline Others & 33,050 & - & - & 33,280 & - & - \\
\hline
\end{tabular}

a) DAV: $\delta$-Aminovaleric acid. ${ }^{b)}$ Molar amt, was calculated from the Sp. Act. c) Supernate: Supernatant fluid.

d) Unidentified compd. were shown as $X_{1}, X_{2}$, and $X_{3}$ (see Fig. 1c)

Composition of ciliates in this expt.

Entodiniinae, 582
Dasytricha,

24
Isotricha

40 $\times 10^{2} / \mathrm{ml}$ 
larly found in the medium without ciliates after incubation and the amount of radioactivity was almost the same as that in the medium with ciliates, though the compound was absent in the medium before incubation, it was assumed that this compound was formed not by rumen ciliates but by process of incubation in B-9 buffer solution (Table V). From the result with radioactive proline shown before, radioactive compound in the ciliate hydrolysate in this experiment is presumed to be only proline, though it could not be identified owing to low radioactivity here.

Finally, L-arginine- $U-{ }^{14} \mathrm{C}$ was added to the medium and incubated with or without rumen ciliates at $39^{\circ} \mathrm{C}$ for $12 \mathrm{hr}$. Results were shown in Table VI. In this case, high radioactivity was detected in carbon dioxide fraction after incubation with ciliates, while the radioactivity of the ether-soluble fraction of the supernatant fluid of the medium with ciliates was almost similar to that without ciliates. The autoradiogram of the paper chromatogram of amino acids found in the supernatant fluid of the medium with ciliates after incubation revealed the spots of arginine, ornithine, proline, DAV and three other unidentified compounds (Fig. 1c). The amount of ornithine, proline and DAV derived from arginine by the ciliates were estimated by calculation from the specific activity of arginine to be equivalent to $55.4,18.0$ and $0.8 \%$ of added arginine, respectively. Radioactive carbon dioxide could be formed from radioactive urea produced by hydrolysis of radioactive arginine with ornithine as an another product, and if so, the amount of carbon dioxide formed could be estimated to be equivalent to $52.3 \%$ of arginine added (Table VI). One of the unidentified compounds $\left(\mathrm{X}_{1}\right)$ shown in Fig. 1c was presumed to be urea according to the $R f$ values of paper chromatogram. The production of carbon dioxide from urea by rumen ciliates seemed to be a problem, because there have been some reports ${ }^{15 \sim 17}$ ) showing that rumen ciliates did not have ureolytic activity. Rumen ciliates after incubation in this experiment retained
$2.3 \%$ of total radioactivity. But the radioactive compounds in the ciliates were not identified, though they were presumed to be chiefly arginine and proline.

From all these results, rumen ciliate protozoan suspension, which was washed five times with B-9 buffer solution previously, was revealed to have abilities to convert arginine to ornithine, ornithine to proline and proline to DAV, and DAV was thought to be the end product in this successive metabolic pathway.

Acknowledgement. The authors are grateful to Drs. Hiromitsu Ootsuka and Katsumi Hamana, Miyazaki University, for inserting permanent rumen fistula into a goat and to Associate Prof. Michio Miura, Miyazaki University, for giving us facilities to use Amino Acid Autoanalyzer. This work was supported by Radioisotope Laboratory of Miyazaki University.

\section{REFERENCES}

1) L. H. Stickland, Biochem. J., 28, 1746 (1934).

2) L. H. Stickland, ibid., 29, 288 (1935).

3) D. D. Woods, ibid., 30, 1934 (1936).

4) K. El-Shazly, ibid., 51, 647 (1952).

5) B. A. Dehority, R. R. Johnson, O. G. Bentley and A. L. Moxon, Arch. Biochem. Biophys., 78, 15 (1958).

6) T. R. Lewis and R. S. Emergy, J. Dairy Sci., 45, 1363 (1962).

7) T. C. Stadtman, Biochem. J., 62, 614 (1956).

8) R. N. Costilow and L. Laycock, J. Bacterol., 96, 1011 (1968).

9) T. Kamahora, Osaka Daigaku Igaku Zasshi, 8, 455 (1956).

10) H. Hagihara, H. Hayashi, A. Ichihara and M. Suda, J. Biochem. (Tokyo), 48, 267 (1960).

11) R. Onodera and M. Kandatsu, Agric. Biol. Chem., 39, 1239 (1975).

12) W. Tsutsumi, R. Onodera and M. Kandatsu, ibid., 39, 711 (1975).

13) R. Onodera and M. Kandatsu, Jap. J. Zootech. Sci., 41, 343 (1970).

14) R. Onodera and M. Kandatsu, ibid., 39, 206 (1968).

15) A. R. Abou Akkada and B. H. Howard, Biochem. J., 82, 313 (1962).

16) M. Kandatsu and N. Takahashi, Nippon Nôgeikagaku Kaishi, 37, 486 (1963).

17) M. A. Naga and K. El-Shazly, J. Gen. Microbiol., 53, 305 (1968). 